\title{
The evolution of infalling sulfur species in Titan's atmosphere
}

\author{
K. M. Hickson ${ }^{1,2}$, J. C. Loison ${ }^{1,2}$, T. Cavaliée 3 , E. Hébrard ${ }^{4}$, and M. Dobrijevic ${ }^{5,6}$ \\ 1 Univ. Bordeaux, ISM, UMR 5255, 33400 Talence, France \\ 2 CNRS, ISM, UMR 5255, 33400 Talence, France \\ 3 Max-Planck-Institut für Sonnensytemforschung, 37077 Göttingen, Germany \\ ${ }^{4}$ Laboratoire Réactions et Génie des Procédés, CNRS, Université de Lorraine, Nancy, France \\ 5 Univ. Bordeaux, LAB, UMR 5804, 33270 Floirac, France \\ e-mail: michel.dobrijevic@obs.u-bordeaux1.fr \\ ${ }^{6}$ CNRS, LAB, UMR 5804, 33270 Floirac, France
}

Received 29 July 2014 / Accepted 19 September 2014

\begin{abstract}
Aims. We studied the hypothesis that micrometeorites and Enceladus' plume activity could carry sulfur-bearing species into the upper atmosphere of Titan, in a manner similar to oxygen-bearing species.

Methods. We have developed a detailed photochemical model of sulfur compounds in the atmosphere of Titan that couples hydrocarbon, nitrogen, oxygen, and sulfur chemistries.

Results. Photochemical processes produce mainly $\mathrm{CS}$ and $\mathrm{H}_{2} \mathrm{CS}$ in the upper atmosphere of Titan and $\mathrm{C}_{3} \mathrm{~S}, \mathrm{H}_{2} \mathrm{~S}$ and $\mathrm{CH}_{3} \mathrm{SH}$ in the lower atmosphere. Mole fractions of these compounds depend significantly on the source of sulfur species.

Conclusions. A possible future detection of CS (or the determination of a low upper limit) could be used to distinguish the two scenarios for the origin of sulfur species, which then could help to differentiate the various scenarios for the origin of $\mathrm{H}_{2} \mathrm{O}, \mathrm{CO}$, and $\mathrm{CO}_{2}$ in the stratosphere of Titan.
\end{abstract}

Key words. planets and satellites: individual: Titan - planets and satellites: atmospheres - planets and satellites: composition

\section{Introduction}

Three oxygen-bearing species $\left(\mathrm{CO}, \mathrm{CO}_{2}\right.$, and $\left.\mathrm{H}_{2} \mathrm{O}\right)$ have been unambiguously identified in the atmosphere of Titan (Lutz et al. 1983; Samuelson et al. 1983; Coustenis et al. 1998), but the origin of these compounds is a matter of debate. In particular, the source of $\mathrm{CO}$ (primordial/external) is still uncertain (Hörst et al. 2008). Moreno et al. (2012) have recently investigated the potential $\mathrm{H}_{2} \mathrm{O}$ sources of Titan's atmosphere. While the Enceladus' plume activity is likely to be responsible for introducing $\mathrm{H}_{2} \mathrm{O}$ into Saturn's atmosphere (Hartogh et al. 2011), Moreno et al. (2012) find that a micrometeoritic source of water could explain their Titan observations equally well. However, the observed $\mathrm{CO}_{2}$ column abundance could not be reproduced by their derived $\mathrm{OH} / \mathrm{H}_{2} \mathrm{O}$ influx, unless the $\mathrm{OH} / \mathrm{H}_{2} \mathrm{O}$ flux decreased over the past few centuries. The cryovolcanism source on Enceladus was then tentatively favored by Moreno et al. (2012) as being more prone to temporal variations than a flux of micrometeorites.

Dobrijevic et al. (2014) modeled Titan's coupled oxygen and nitrogen photochemistry and confirmed that these scenarios are indeed possible. Although the origin of the discrepancy in the $\mathrm{H}_{2} \mathrm{O} / \mathrm{CO}_{2}$ abundance ratio was not completely resolved, its magnitude was decreased by a factor of 4 with their model. In addition, they show that the eventual detection of compounds, such as NO (nitric oxide), HNO (nitrosyl hydride), HNCO (isocyanic acid), and $\mathrm{N}_{2} \mathrm{O}$ (nitrous oxide), could help to distinguish between these scenarios. In a complementary study, Lara et al. (2014) tried to waive the apparent discrepancy seen in the $\mathrm{H}_{2} \mathrm{O}$ and $\mathrm{CO}_{2}$ influx rates. With their time-dependent model, they inferred a decrease by a factor of 5-20 of the Enceladus plume activity in the past few centuries to reconcile the data. Though possible in principle and in agreement with the observations, supply of an excess of $\mathrm{CO}_{2}$ subsequent to a comet impact was deemed very unlikely because of the extremely low comet impact rate at Titan.

Predicting and quantifying the presence of N-O species, as presented in Dobrijevic et al. (2014) was a first logical attempt to place additional observational constraints on the source of external oxygen, given the high $\mathrm{N}_{2}$ abundance in Titan's atmosphere. In the present paper, we look for additional constraints that could arise from other species potentially carried along by the same external source as for oxygen, namely sulfur-bearing compounds, and quantify their subsequent coupled photochemistry. First, we should point out that given the low temperature at the tropopause, the maximum hydrogen sulfide $\left(\mathrm{H}_{2} \mathrm{~S}\right)$ mole fraction expected to be present in the stratosphere of Titan from internal sources (e.g., cryovolcanism) is extremely low (about $10^{-15}$ ). Moreover, other potential internal sources of sulfur $\left(\mathrm{CS}_{2}, \mathrm{OCS}, \mathrm{H}_{2} \mathrm{SO}_{4}, \mathrm{CaSO}_{4}, \mathrm{FeS}\right.$ (troilite), $\left.\mathrm{S}_{8}\right)$ will also condense below the tropopause. The presence of a sulfur species in Titan's stratosphere would thus imply an external source for sulfur. Several sulfur-bearing species have been detected in comets, among which $\mathrm{H}_{2} \mathrm{~S}$ and carbon monosulfide (CS) are the most abundant (Crovisier et al. 2009) with a total sulfur compound mixing ratio in the range $\left[10^{-3}, 10^{-2}\right] . \mathrm{H}_{2} \mathrm{~S}$ has also been detected in Enceladus' plumes, but its mixing ratio is much lower: $(2 \pm 1) \times 10^{-5}$ (Waite et al. 2009). These two potential sources of sulfur are then significantly different in magnitude. Our goal is to propose the first photochemical model for the atmosphere of Titan that accounts for sulfur species and to investigate whether the photochemical processes driven by the possible influx of 
A\&A 572, A58 (2014)

Table 1. Boundary conditions for oxygen and sulfur species at the upper (for fluxes) and lower (for CO) boundaries of our three models.

\begin{tabular}{lccccccc}
\hline \hline Source & Model & $\mathrm{H}_{2} \mathrm{O}$ Flux & $\mathrm{O}^{3}$ P) Flux & CO mole fraction & $\mathrm{H}_{2}$ S Flux (a) & OCS Flux (a) & CS $_{2}$ Flux (a) \\
\hline Micrometeorites ablation & $\mathrm{A} 1$ & $5.2 \times 10^{5}$ & $1.6 \times 10^{6}$ & $5.1 \times 10^{-5}$ & $1.5 \times 10^{-2}$ & $4 \times 10^{-3}$ & $2 \times 10^{-3}$ \\
& $\mathrm{~A} 2$ & $2.6 \times 10^{6}$ & 0 & $5.1 \times 10^{-5}$ & $1.5 \times 10^{-2}$ & $4 \times 10^{-3}$ & $2 \times 10^{-3}$ \\
\hline Enceladus & $\mathrm{B}$ & $6.5 \times 10^{5}$ & $1.6 \times 10^{6}$ & $5.1 \times 10^{-5}$ & $10^{-5}$ & 0 & 0 \\
\hline
\end{tabular}

Notes. Fluxes are expressed in $\mathrm{cm}^{-2} \mathrm{~s}^{-1}$ and referred to the surface. The peak for the production of $\mathrm{H}_{2} \mathrm{O}$ by micrometeorite ablation occurs around an altitude of $750 \mathrm{~km}$. (a) relative to the $\mathrm{H}_{2} \mathrm{O}$ flux.

these molecules would be efficient enough to produce sulfur species at a detectable level and if these species would enable differentiating their possible external sources.

The possible detection of sulfur species in the atmosphere of Titan could help to better constrain the relative importance of the physical processes that bring sulfur and oxygen from the interplanetary medium. To date, no sulfur-bearing molecule has been detected in the atmosphere of Titan. Nixon et al. (2013) searched unsuccessfully for $\mathrm{H}_{2} \mathrm{~S}$, thereby placing an upper limit on its stratospheric abundance equal to $330 \mathrm{ppb}$ (at the $2-\sigma$ significance level). In the present paper, we study the photochemistry of sulfur compounds subsequent to a possible external delivery from two different sources (micrometeorites and Enceladus' plume activity) to quantify the abundances of sulfur-bearing species resulting from such sources. In Sect. 2, we present the photochemical model and boundary conditions. The methodology for deriving the chemical scheme is presented in Sect. 3. Model results and their uncertainties are presented in Sects. 4 and 5, respectively. We then conclude in Sect. 6.

\section{Photochemical model}

The photochemical model and the atmospheric structure are described in Dobrijevic et al. (2014) and Loison et al. (2014) and are not repeated here. We only present modifications specific to the photochemistry of sulfur species.

\subsection{Boundary conditions}

In the present paper, we study two sources of oxygen and sulfur species: micrometeorite ablation in the upper stratosphere and the influx at the top of the atmosphere from Enceladus' plume activity. We consider that micrometeorite ablation is a source of sulfur species in the atmosphere of Titan in the same way as for water (see Dobrijevic et al. 2014). We then use fluxes of sulfur species that reflect their relative abundances in comets. We also consider that ablation processes do not change the nature of the main sulfur species present in comets. According to Jackson et al. (1982), the parent molecule of CS detected in comets is $\mathrm{CS}_{2}$, so we consider an influx of $\mathrm{CS}_{2}$ rather than CS. Despite the broad chemical diversity among comets revealed by radio spectroscopy, Crovisier et al. (2009) state that there is no obvious correlation between chemical diversity and the dynamical classes of comets. Based on the study of about 30 comets, they find that the molecular abundances relative to water for $\mathrm{H}_{2} \mathrm{~S}$ and $\mathrm{CS}_{2}$ are in the ranges $\left[10^{-3}, 10^{-2}\right]$ and $\left[2 \times 10^{-4}\right.$, $2 \times 10^{-3}$ ], respectively. In C/1995 O1 (Hale-Bopp) and C/1996 B2 (Hyakutake), the production rates relative to water of $\mathrm{H}_{2} \mathrm{~S}$ was $1.5 \%$ and $0.8 \%$, respectively, whereas they were $0.2 \%$ and $0.1 \%$ for $\mathrm{CS}_{2}$. For these two comets, the ratio $\mathrm{H}_{2} \mathrm{~S} / \mathrm{CS}_{2}$ is roughly 8 . In $1 \mathrm{P} / \mathrm{Halley}$, the production rate of $\mathrm{H}_{2} \mathrm{~S}$ is two times less than in Hyakutake, and the ratio $\mathrm{H}_{2} \mathrm{~S} / \mathrm{CS}_{2}$ is only 2 . We also take OCS into account, which has been detected in Hale-Bopp with an abundance relative to $\mathrm{H}_{2} \mathrm{O}$ of $0.4 \%$ (Bockelée-Morvan et al. 2000) and in Hyakutake with an abundance of $0.1 \%$ (Woodney et al. 1997). $\mathrm{SO}_{2}$ has been also detected in HaleBopp with a relative abundance of $0.2 \%$ (Bockelée-Morvan et al. 2000) but the photolysis of $\mathrm{SO}_{2}$ in Titan's atmosphere will ultimately produce $\mathrm{S}$ atoms (see discussion Sect. 3). In the following, we then consider the most favorable proportion of sulfur species in comets and neglect the presence of $\mathrm{SO}_{2}$ (see Table 1). For the Enceladus source, only the flux of $\mathrm{H}_{2} \mathrm{~S}$ is taken into consideration since it is the sole sulfur-bearing species detected so far in the plumes (Waite et al. 2009).

Boundary conditions for the oxygen species for the micrometeorite ablation source are based on scenarios IM1 and IM3 from Dobrijevic et al. (2014) corresponding to an internal origin of $\mathrm{CO}$, a water influx by micrometeorites ablation, and an influx of oxygen atoms, assuming that all $\mathrm{O}^{+}$ions precipitate from Saturn's magnetosphere in the form of $\mathrm{O}\left({ }^{3} \mathrm{P}\right)$ atoms at the top of the atmosphere (Hörst et al. 2008). We consider two models to explore the range of water influxes, which give $\mathrm{H}_{2} \mathrm{O}$ profiles in agreement with observations of Moreno et al. (2012; model A1) and Cottini et al. (2012; model A2). Model A1 corresponds to our nominal model, whereas model A2 can be considered as the upper limit of $\mathrm{H}_{2} \mathrm{O}$ influx (and so the upper limit of $\mathrm{H}_{2} \mathrm{~S}$ influx from micrometeorite ablation). Boundary conditions for the oxygen species for the Enceladus source are based on scenario IE2 from Dobrijevic et al. (2014), and they give $\mathrm{H}_{2} \mathrm{O}$ profiles in agreement with observations of Moreno et al. (2012; model B). Because $\mathrm{H}_{2} \mathrm{O}$ was detected in gaseous form in the Enceladus torus (Hartogh et al. 2011), $\mathrm{H}_{2} \mathrm{O}$ is deposited in its gaseous form at the top of the atmosphere (as well as $\mathrm{H}_{2} \mathrm{~S}$ ).

\subsection{Condensation}

Several sulfur species condense in the lower atmosphere of Titan. The saturated vapor pressure expressions are given in Table 2. For $\mathrm{H}_{2} \mathrm{CS}$ and $\mathrm{C}_{3} \mathrm{~S}$, we did not find any expressions for the saturated vapor pressure in the literature. We assume that they are identical to the ones of $\mathrm{H}_{2} \mathrm{CO}$ and $\mathrm{CH}_{3} \mathrm{C}_{2} \mathrm{H}$, respectively. The tropopause acts as a very efficient cold trap for sulfur species that could originate in a cryogenic source. For instance, the mole fractions at saturation of OCS, $\mathrm{H}_{2} \mathrm{~S}$, and $\mathrm{CS}_{2}$ at the tropopause $(T=67.55 \mathrm{~K})$ are $1.0 \times 10^{-14}, 5.7 \times 10^{-16}$ and $3.5 \times 10^{-29}$, respectively.

\section{Chemical scheme}

We use the chemical scheme of Loison et al. (2014) for H, C, N, and $\mathrm{O}$. In the following, we present the methodology we used to construct the sulfur chemical scheme. Because $\mathrm{H}_{2} \mathrm{~S}$ and $\mathrm{CS}_{2}$ react slowly with $\mathrm{H}$ atoms, sulfur chemistry is initiated by $\mathrm{H}_{2} \mathrm{~S}$ and $\mathrm{CS}_{2}$ photodissociation. We then constructed the chemical scheme considering all the main reactions at each step (determined from the calculations of production and loss rates) for the 
Table 2. Saturated vapor pressure of sulfur species in the model (from NIST database).

\begin{tabular}{llc}
\hline \hline Species & Saturated vapor pressure & $T$ validity range $[\mathrm{K}]$ \\
\hline $\mathrm{H}_{2} \mathrm{~S}$ & $\log _{10}(P)=4.43681-829.439 /(T-25.412)$ & {$[138.8,212.8]$} \\
$\mathrm{OCS}$ & $\log _{10}(P)=4.0436-808.49 /(T-22.72)$ & {$[161.8,223.84]$} \\
$\mathrm{CH}_{3} \mathrm{SH}$ & $\log _{10}(P)=4.19201-1031.431 /(T-32.72)$ & {$[221.87,279.13]$} \\
$\mathrm{CS}_{2}$ & $\log _{10}(P)=4.06683-1168.62 /(T-31.616)$ & {$[276.74,353.08]$} \\
$\mathrm{CH}_{3} \mathrm{CHS}$ & $\log _{10}(P)=4.15626-1190.802 /(T-41.175)$ & {$[291.44,360.88]$} \\
\hline
\end{tabular}

Notes. $P$ in bar and $T$ in $\mathrm{K}$.

Table 3. The 26 sulfur species considered in this study.

\begin{tabular}{lcc}
\hline \hline Family & Number & Species \\
\hline $\mathrm{H}-\mathrm{S}$ & 4 & $\mathrm{~S}^{3}(\mathrm{P}), \mathrm{S}^{1}(\mathrm{D}), \mathrm{SH}, \mathrm{H}_{2} \mathrm{~S}$ \\
$\mathrm{C}-\mathrm{S}$ & 17 & $\mathrm{CS}, \mathrm{HCS}, \mathrm{H}_{2} \mathrm{CS}, \mathrm{CH}_{3} \mathrm{~S}, \mathrm{CH}_{3} \mathrm{SH}$ \\
& & $\mathrm{C}_{2} \mathrm{~S}, \mathrm{HCCS}, \mathrm{C}_{2} \mathrm{H}_{2} \mathrm{~S}, \mathrm{H}_{2} \mathrm{CCS}, \mathrm{CH}_{3} \mathrm{CS}$ \\
& & $\mathrm{CH}_{3} \mathrm{CHS}_{2} \mathrm{C}_{2} \mathrm{H}_{4} \mathrm{~S}, \mathrm{C}_{3} \mathrm{~S}$, \\
& & $\mathrm{HC}_{3} \mathrm{~S}, \mathrm{H}_{2} \mathrm{C}_{3} \mathrm{~S}, \mathrm{CS}_{2}, \mathrm{H}_{2} \mathrm{C}_{5} \mathrm{~S}$ \\
N-S & 4 & $\mathrm{NS}, \mathrm{NCS}, \mathrm{HNCS}, \mathrm{N}_{2} \mathrm{~S}$ \\
O-S & 1 & OCS \\
\hline Total & 26 & \\
\hline
\end{tabular}

various species produced from the previous step. All closed-shell molecules containing sulfur that could potentially be present in Titan's atmosphere have low to very low reactivity with $\mathrm{H}$ and $\mathrm{CH}_{3}$. However, they all have appreciable absorption crosssections in the 200-300 $\mathrm{nm}$ range, where the solar flux is large. As a result, they are all easily photodissociated because S-H or $\mathrm{C}-\mathrm{S}$ bonds are relatively fragile. Exceptions include $\mathrm{N}_{2} \mathrm{~S}$, which has very low absorption above $200 \mathrm{~nm}$, and $\mathrm{CS}$ and $\mathrm{C}_{3} \mathrm{~S}$, which are not photodissociated at wavelengths greater than $168 \mathrm{~nm}$ and $182 \mathrm{~nm}$, respectively.

All sulfur atoms and radicals ( $\mathrm{S}, \mathrm{SH}, \mathrm{HCS}$, etc.) react with $\mathrm{H}$ atoms and/or with $\mathrm{CH}_{3}$ radicals, so that these reactions dominate the losses for these species. $\mathrm{CS}$ and $\mathrm{C}_{3} \mathrm{~S}$ are special cases because they are not easily photodissociated due to their high bond strengths. Nevertheless, $\mathrm{CS}$ and $\mathrm{C}_{3} \mathrm{~S}$ are substantially more reactive than their oxygen-bearing counterparts, and they reach steady state abundances much faster than CO. In Titan's atmosphere, the abundances of reactive oxygen compounds $(\mathrm{O}, \mathrm{OH})$ are too low to compete with $\mathrm{H}$ and $\mathrm{CH}_{3}$ reactions to produce $\mathrm{S}-\mathrm{O}$ species efficiently. We then neglected most of the crossed oxygen-sulfur reactions and introduce neither SO nor $\mathrm{SO}_{2}$ molecules because their formation rates are low and they are easily photodissociated in the UV. Sulfur atoms have similar electronic properties to oxygen atoms so it is interesting to compare and contrast both chemical networks for Titan's atmosphere. The main differences between our oxygen and sulfur schemes are that $\mathrm{H}_{2} \mathrm{~S}$ is easily photodissociated between 180 and $230 \mathrm{~nm}$ and is not produced through the reactions $\mathrm{SH}+\mathrm{CH}_{3}$ or $\mathrm{SH}+\mathrm{CH}_{4}$ and that $\mathrm{SH}$ reacts with $\mathrm{H}$ atoms leading to $\mathrm{S}$ atom formation. $\mathrm{H}_{2} \mathrm{~S}$ production is inefficient (except in the very lower atmosphere below $200 \mathrm{~km}$ ), and $\mathrm{CS}$ (and $\mathrm{C}_{3}$ S) reacts with $\mathrm{C}_{2} \mathrm{H}_{3}$ in contrast to $\mathrm{CO}$.

For each important reaction we performed an extensive bibliographic review that included chemical databases such as the KIDA database (Wakelam et al. 2012). When no information existed, we calculated the presence and the value of the entrance barrier using density functional theory (DFT) calculations (with the hybrid M06-2X functional developed by Zhao \& Truhlar 2008), which is well suited to calculations involving molecules and radicals with $\mathrm{C}, \mathrm{N}, \mathrm{H}, \mathrm{O}$, and $\mathrm{S}$ atoms, associated with aug-cc-pVTZ basis sets (Dunning 1989) using
Gaussian09 (11 reactions are concerned). For barrierless reactions, the rate constants $k(T)$ were calculated using simplified capture rate theory, which led to an upper limit value of the rate constant (Georgievskii \& Klippenstein 2005). For reactions with a barrier, the rate constants were calculated using conventional transition state theory or are estimated by comparison with similar reactions involving oxygen analogs. Particular attention was paid to photodissociation processes. When no data existed, the absorption cross section were calculated using the EOM-aug-ccpVTZ method using Gaussian09.

Branching ratios for the photolysis of sulfur containing species are poorly known. When no data exist they are deduced from the oxygen analogs or deduced from thermodynamic data leading to large uncertainties. The present chemical scheme contains 153 species (26 sulfur species), 1060 reactions (91 including sulfur species), 199 photolysis processes (28 including sulfur species), and the dissociation of $\mathrm{N}_{2}$ by galactic cosmic rays. The coupling between sulfur chemistry and nitrogen or oxygen chemistry is limited to the main compounds. The complete list of reactions, with references or information regarding the estimation of rate constants and their uncertainty factors, is available upon request and can be downloaded from the KIDA database (Wakelam et al. 2012).

\section{Results}

\subsection{Oxygen species}

As a first step in our study, we set the oxygen flux from the micrometeorites ablation and Enceladus sources in order to have $\mathrm{a}_{2} \mathrm{O}$ mole fraction profile in agreement with observations (see Fig. 1). Models A1 and B lead to a good agreement with Moreno et al. (2012), whereas model A2 can be considered as an upper limit for the flux of water, in agreement with the abundances derived by Cottini et al. (2012) (see Dobrijevic et al. 2014 for details). Lara et al. (2014) investigated the temporal variability of Enceladus' plume activity or comet impacts as possible sources of oxygen to reconcile both observations of $\mathrm{H}_{2} \mathrm{O}$ and $\mathrm{CO}_{2}$. In the present study, we focus on the photochemistry of sulfur species, and the results we present were obtained at steady state to limit the number of parameters.

\subsection{Sulfur species}

In a second step, we considered that micrometeorite ablation leads to sulfur in the form of $\mathrm{H}_{2} \mathrm{~S}$, OCS, and $\mathrm{CS}_{2}$ in a similar manner to $\mathrm{H}_{2} \mathrm{O}$, with fluxes in agreement with the relative abundances of $\mathrm{H}_{2} \mathrm{~S}, \mathrm{OCS}$, and $\mathrm{CS}_{2}$ in comets. The results for the most abundant sulfur species are presented in Fig. 2. Mole fractions are very low throughout the atmosphere. In the best scenario, $\mathrm{CS}$ is the most abundant species and can reach a mole fraction of about $7 \mathrm{ppb}$ around an altitude of $900 \mathrm{~km}$. The upper limit on $\mathrm{H}_{2} \mathrm{~S}$ mole fractions ( $330 \mathrm{ppb}$ at 0.27 mbar) derived by Nixon et al. (2013) from Cassini CIRS data is four orders of magnitude higher than the value we obtain in the best case. 


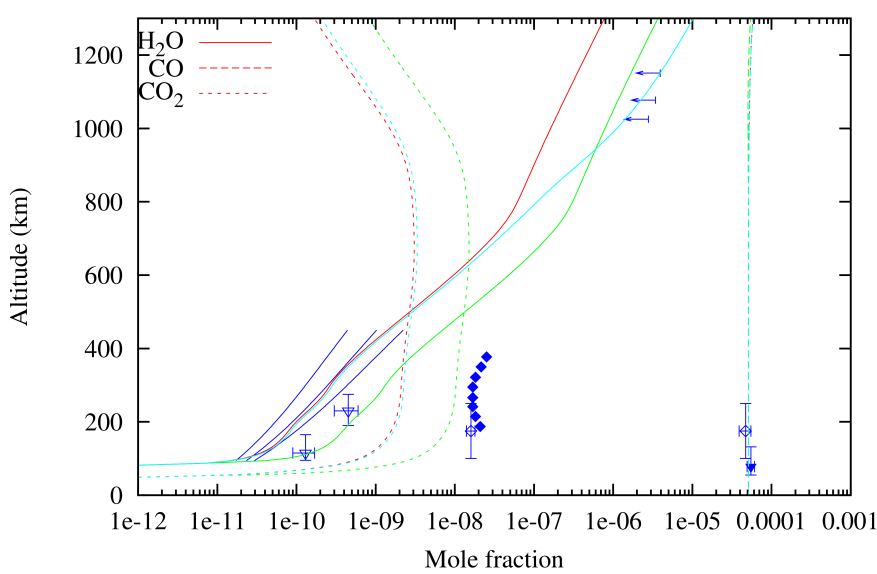

Fig. 1. $\mathrm{H}_{2} \mathrm{O}$ (solid line), $\mathrm{CO}$ (long dashed line), and $\mathrm{CO}_{2}$ (short dashed line) mole fractions as a function of altitude for the three models listed in Table 1. Observations (in blue) from Moreno et al. (2012) (solid lines for mean and 1- $\sigma$ uncertainty), Cottini et al. (2012) (open triangles), and upper limits from INMS data (Cui et al. 2009) for $\mathrm{H}_{2} \mathrm{O}$, from de Kok et al. (2007) for $\mathrm{CO}$ and $\mathrm{CO}_{2}$ (open diamonds), from Vinatier et al. (2010) for $\mathrm{CO}_{2}$ (filled diamonds), and from Teanby et al. (2010) for $\mathrm{CO}$ (filled triangle) are shown for comparison. Red: Model A1. Green: Model A2. Cyan: Model B. Blue: observations.
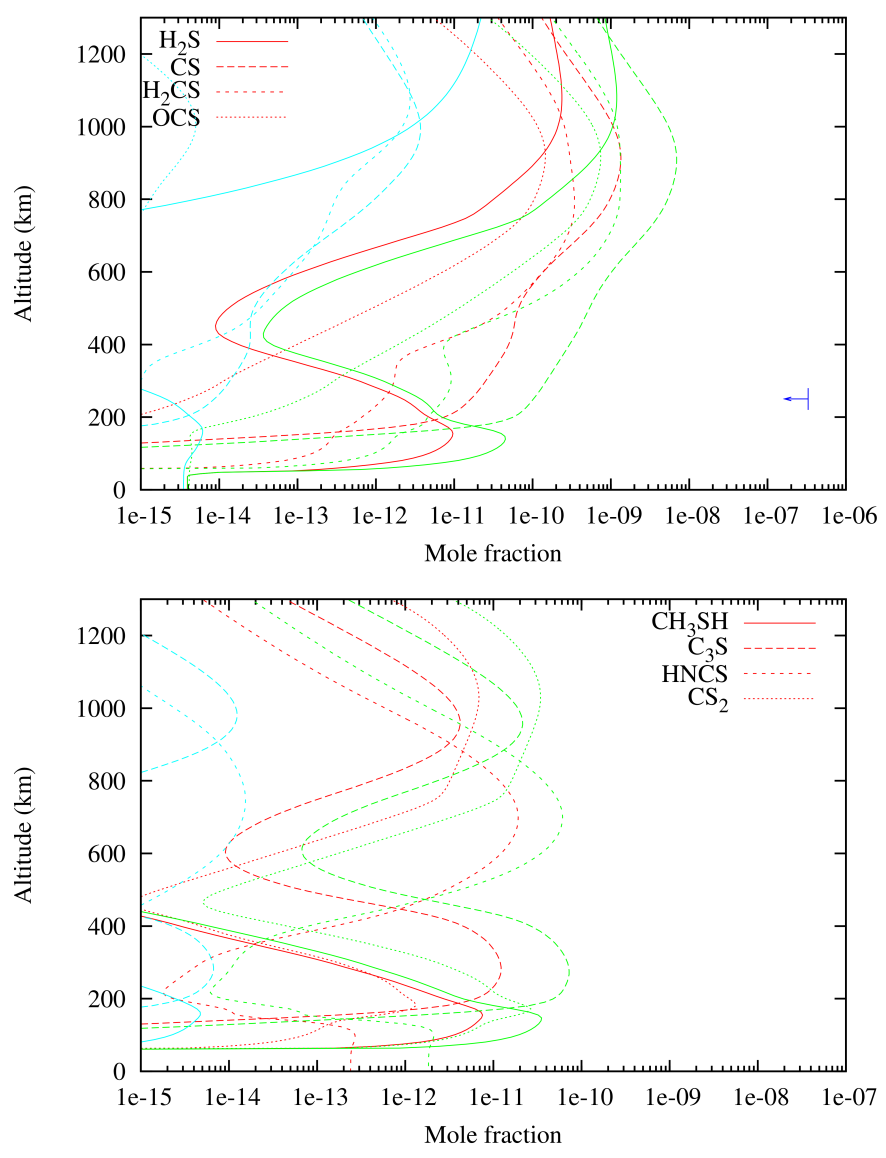

Fig. 2. Mole fraction profiles of main sulfur species. Red: Model A1. Green: Model A2. Cyan: Model B. Top: $\mathrm{H}_{2} \mathrm{~S}, \mathrm{CS}$, OCS and $\mathrm{H}_{2} \mathrm{CS}$. The upper limit of $\mathrm{H}_{2} \mathrm{~S}$ from Nixon et al. (2013) is shown in blue. Bottom: $\mathrm{CH}_{3} \mathrm{SH}, \mathrm{C}_{3} \mathrm{~S}, \mathrm{HNCS}$ and $\mathrm{CS}_{2}$.

We performed several tests to study the sensitivity of sulfurbearing species and, in particular CS, to some hypothesis we have made. Replacing $\mathrm{H}_{2} \mathrm{~S}$ by $\mathrm{SH}$ in Model A2 for instance has

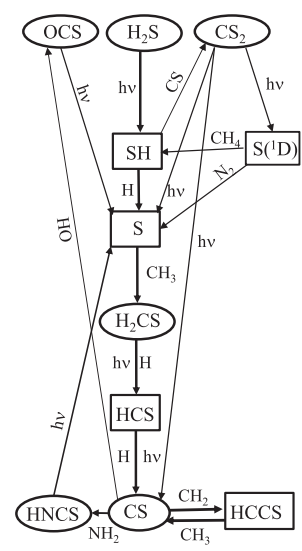

Upper Atmosphere

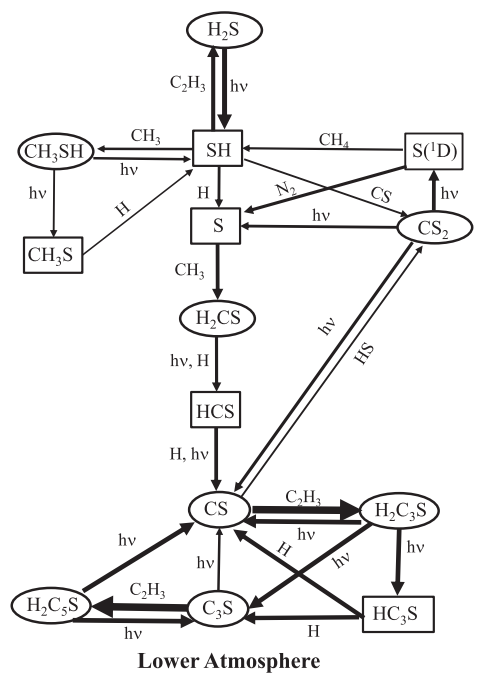

Fig. 3. Schematic diagrams highlighting the important neutral reaction pathways for the production of sulfur species in the higher part of the atmosphere (left) and in the lower stratosphere (right). The thickness of each arrow is proportional to the integral of the total production rate over the atmosphere. These main reactions pathways are identical for the three models considered in the present study. Radicals are shown in boxes, whereas stable compounds are shown in circles.

no significant effect on the abundances of sulfur compounds (except for $\mathrm{H}_{2} \mathrm{~S}$ ). As an additional test, we set the fluxes of $\mathrm{CS}_{2}$ and OCS to zero to examine their importance in the photochemical processes. This modification was also found to have little effect on the CS abundance.

Although the relative magnitude of the $\mathrm{H}_{2} \mathrm{~S}$, OCS, and $\mathrm{CS}_{2}$ influxes are identical between Models A1 and A2, our results show different behaviors for the mole fraction profiles of some sulfur-bearing species. For instance, from Model A1 to Model A2, the mole fractions of $\mathrm{HNCS}, \mathrm{C}_{3} \mathrm{~S}, \mathrm{H}_{2} \mathrm{CS}$, and CS increase by factors of $3,5,5$, and 6 , respectively (for altitudes around $600-1200 \mathrm{~km}$ ). The lower increase of HNCS is due to the fact that $\mathrm{NH}_{2}+\mathrm{CS}$ and $\mathrm{NH}_{2}+\mathrm{CH}_{3}$ are the main reactions responsible of $\mathrm{NH}_{2}$ consumption. Then, an increase in CS abundance leads to a decrease in $\mathrm{NH}_{2}$, and consequently the production rate of the $\mathrm{NH}_{2}+\mathrm{CS}$ reaction stays almost constant.

We tested the Enceladus source scenario by setting fluxes of $\mathrm{H}_{2} \mathrm{O}$ and $\mathrm{H}_{2} \mathrm{~S}$ that are representative of the Enceladus source at the top of the atmosphere (Model B, see Table 1). Owing to the low relative abundance of $\mathrm{H}_{2} \mathrm{~S}$ compared to $\mathrm{H}_{2} \mathrm{O}$ in Enceladus' plumes, the mole fraction of $\mathrm{H}_{2} \mathrm{~S}$ we found in our model is very low: the maximum is $2 \times 10^{-11}$ at an altitude of $1300 \mathrm{~km}$ and decreases to $10^{-15}$ at $800 \mathrm{~km}$. In this case, the peak value of the CS mole fraction is only $4 \times 10^{-12}$ around $900-1000 \mathrm{~km}$.

The chemical lifetimes of the various sulfur species are relatively short (around 35 days for $\mathrm{CS}$ and 3.5 days for $\mathrm{H}_{2} \mathrm{~S}$ at $900 \mathrm{~km}$ of altitude for instance), so in principle, it might be possible to follow the temporal variability of the input fluxes by monitoring sulfur-containing species such as CS. This is in stark contrast to the oxygen case given the extremely long lifetime of CO.

In the upper atmosphere (above $600 \mathrm{~km}$ ), sulfur chemistry is dominated by the rapid transformation of $\mathrm{H}_{2} \mathrm{~S}$ into $\mathrm{CS}$ (see Fig. 3, left). $\mathrm{SH}$ or $\mathrm{S}\left({ }^{3} \mathrm{P}\right)$ are produced efficiently by $\mathrm{H}_{2} \mathrm{~S}$ photolysis below $316 \mathrm{~nm}$ (Feng et al. 1999; Watanabe \& Jursa 1964; Hsu et al. 1992):

$\mathrm{H}_{2} \mathrm{~S}+\mathrm{h} v \rightarrow \mathrm{SH}+\mathrm{H}$. 
By comparison with the oxygen chemistry, $\mathrm{SH}$ does not lead to $\mathrm{H}_{2} \mathrm{~S}$ formation through reaction with $\mathrm{CH}_{3}$ or $\mathrm{CH}_{4}$ but leads instead to $\mathrm{S}\left({ }^{3} \mathrm{P}\right)$ through the reaction

$\mathrm{H}+\mathrm{SH} \rightarrow \mathrm{S}+\mathrm{H}_{2} \quad k(T)=3.0 \times 10^{-11} \mathrm{~cm}^{3} \mathrm{~s}^{-1}$

(Cupitt \& Glass 1975; Peng et al. 1999). Then, the sulfur-atom production is much more efficient than oxygen-atom production, leading to substantial $\mathrm{H}_{2} \mathrm{CS}$ production through the reaction

$\mathrm{S}+\mathrm{CH}_{3} \rightarrow \mathrm{H}_{2} \mathrm{CS}+\mathrm{H} \quad k(T)=1.4 \times 10^{-10} \mathrm{~cm}^{3} \mathrm{~s}^{-1}$

(rate constant estimated by comparison with $\mathrm{O}+\mathrm{CH}_{3}$, Baulch et al. 2005). Since $\mathrm{H}_{2} \mathrm{CS}$ is readily photodissociated in the UV $(\lambda<312 \mathrm{~nm})$, leading to $\mathrm{H}+\mathrm{HCS}$ products, $\mathrm{CS}$ is then produced by the following reactions:

$\mathrm{H}_{2} \mathrm{CS}+\mathrm{h} v \rightarrow \mathrm{HCS}+\mathrm{H}$

(cross section and quantum yield from this work and Judge et al. 1978), and

$\mathrm{H}+\mathrm{HCS} \rightarrow \mathrm{CS}+\mathrm{H}_{2} \quad k(T)=1.0 \times 10^{-10} \mathrm{~cm}^{3} \mathrm{~s}^{-1}$

(rate constant estimated by comparison with $\mathrm{H}+\mathrm{HCO}$, Baulch et al. 2005).

Above $600 \mathrm{~km}, \mathrm{CS}$ is a relatively non-reactive species. Indeed, CS has similar properties and structure to CO. CS is seen to polymerize spontaneously through wall reactions (Moltzen et al. 1988; Wollrab \& Rasmussen 1973) but does not polymerize in the gas phase. Moreover, CS does not react with the main molecules and radicals present above $600 \mathrm{~km}$. (CS is not reactive with $\mathrm{CH}_{3}$ radicals and the $\mathrm{H}+\mathrm{CS} \rightarrow \mathrm{HCS}$ association reaction is efficient only at high pressure.) The main reaction of CS above $600 \mathrm{~km}$ is with $\mathrm{CH}_{2}$ radicals,

$\mathrm{CS}+\mathrm{CH}_{2} \rightarrow \mathrm{HCCS}+\mathrm{H} \quad k(T)=6.0 \times 10^{-11} \mathrm{~cm}^{3} \mathrm{~s}^{-1}$

(rate constant estimated using theoretical calculations and capture rate theory), which involves relatively low production rates. Consequently, the main sulfur compounds above $600 \mathrm{~km}$ are CS and $\mathrm{H}_{2} \mathrm{CS}$.

The situation is completely different below $400 \mathrm{~km}$ (see Fig. 3, right). Using the rate constant from Vuitton et al. (2012) for the three body reaction $\mathrm{H}+\mathrm{C}_{2} \mathrm{H}_{2}$, we find that the $\mathrm{C}_{2} \mathrm{H}_{3}$ abundance is similar to $\mathrm{CH}_{3}$ in the $100-200 \mathrm{~km}$ range, and we obtain a notable decrease in the $\mathrm{H}$-atom concentration $([\mathrm{H}]<$ $\left[\mathrm{CH}_{3}\right]$ and $\left.\left[\mathrm{C}_{2} \mathrm{H}_{3}\right]\right) \cdot \mathrm{C}_{2} \mathrm{H}_{3}$ is a significantly more reactive radical than $\mathrm{CH}_{3}$ or $\mathrm{C}_{2} \mathrm{H}_{5}$, so we performed DFT and MP2 calculations for the $\mathrm{CS}+\mathrm{C}_{2} \mathrm{H}_{3}$ reaction, finding no barrier for this process:

$\mathrm{CS}+\mathrm{C}_{2} \mathrm{H}_{3} \rightarrow \mathrm{H}_{2} \mathrm{C}_{3} \mathrm{~S}+\mathrm{H} \quad k(T)=3.0 \times 10^{-11} \mathrm{~cm}^{3} \mathrm{~s}^{-1}$

(rate constant estimated using theoretical calculations and capture rate theory). As a result, below $400 \mathrm{~km}$, CS reacts quickly with $\mathrm{C}_{2} \mathrm{H}_{3}$ leading to various complex sulfur compounds, particularly $\mathrm{C}_{3} \mathrm{~S}$, which reaches a maximum mole fraction around $300 \mathrm{~km} . \mathrm{H}_{2} \mathrm{C}_{2} \mathrm{~S}$ and $\mathrm{H}_{2} \mathrm{C}_{5} \mathrm{~S}$ are also efficiently produced, but these two species are also easily photodissociated, so their steady state abundances are quite low. As a result of the $\mathrm{H}$ atom concentration decrease, the $\mathrm{H}+\mathrm{SH}$ reaction becomes much less efficient with a corresponding increase in the $\mathrm{SH}$ mole fraction.

If we consider that the $\mathrm{SH}+\mathrm{CS}$ reaction has no barrier by comparison with the $\mathrm{OH}+\mathrm{CS}$ reaction, we find that $\mathrm{CS}_{2}$ is produced efficiently by

$\mathrm{SH}+\mathrm{CS} \rightarrow \mathrm{CS}_{2}+\mathrm{H} \quad k(T)=2.0 \times 10^{-10} \mathrm{~cm}^{3} \mathrm{~s}^{-1}$
(Rice \& Chabalowski 1994; Loison et al. 2012). In Titan's atmosphere, $\mathrm{CS}_{2}$ is easily photodissociated (its absorption crosssection is greater than $10^{-16} \mathrm{~cm}^{2}$ in the [200-210] nm range), leading to both $\mathrm{S}\left({ }^{3} \mathrm{P}\right)$ and $\mathrm{S}\left({ }^{1} \mathrm{D}\right)$ production via

$$
\begin{aligned}
& \mathrm{CS}_{2}+\mathrm{h} v \stackrel{0.6}{\longrightarrow} \mathrm{CS}+\mathrm{S}\left({ }^{1} \mathrm{D}\right) \\
& \mathrm{CS}_{2}+\mathrm{h} v \stackrel{0.4}{\longrightarrow} \mathrm{CS}+\mathrm{S}\left({ }^{3} \mathrm{P}\right)
\end{aligned}
$$

(Yang et al. 1980; Moltzen et al. 1988) and then to SH production through the reaction

$\mathrm{S}\left({ }^{1} \mathrm{D}\right)+\mathrm{CH}_{4} \rightarrow \mathrm{SH}+\mathrm{CH}_{3} \quad k(T)=1.7 \times 10^{-10} \mathrm{~cm}^{3} \mathrm{~s}^{-1}$

(Black \& Jusinski 1985). Consequently, the SH abundance reaches a maximum around $300 \mathrm{~km}$ (in contrast to the $\mathrm{OH}$ abundance). $\mathrm{SH}$ reacts mainly with $\mathrm{C}_{2} \mathrm{H}_{3}$ below $300 \mathrm{~km}$ :

$$
\mathrm{SH}+\mathrm{C}_{2} \mathrm{H}_{3} \rightarrow \mathrm{H}_{2} \mathrm{~S}+\mathrm{C}_{2} \mathrm{H}_{2} \quad k(T)=5.0 \times 10^{-11} \mathrm{~cm}^{3} \mathrm{~s}^{-1}
$$

(rate constant estimated by comparison with $\mathrm{OH}+\mathrm{C}_{2} \mathrm{H}_{3}$, Tsang \& Hampson 1986). Then $\mathrm{H}_{2} \mathrm{~S}$ becomes the main sulfur species at these altitudes, explaining the strong predicted decrease in the CS mole fraction below $200 \mathrm{~km}$. This is a notable difference with oxygen chemistry in Titan's atmosphere since CO does not show such a decrease in the troposphere.

The reactions with sulfur species are always secondary reactions for hydrocarbons, so they do not affect the abundance profiles of hydrocarbons. This is not the case for $\mathrm{NH}_{2}$ because the reaction $\mathrm{NH}_{2}+\mathrm{CS}$ is one of the main $\mathrm{NH}_{2}$ consumption pathways (see Fig. 3). As a result, the addition of sulfur species in the model also affects $\mathrm{NH}_{3}$ and $\mathrm{CH}_{3} \mathrm{NH}_{2}$ because both species form mainly through reactions involving $\mathrm{NH}_{2}$. The maximum losses for these three species occur around $400 \mathrm{~km}$ and reach factors of 2.7, 2.3, and 2.3 for $\mathrm{NH}_{2}, \mathrm{NH}_{3}$, and $\mathrm{CH}_{3} \mathrm{NH}_{2}$, respectively. These differences fall within the uncertainty limits of their modeled mole fractions (see Loison et al. 2014), so they can hardly serve as a proxy for indirect sulfur detection.

\section{Uncertainty propagation study}

Since many of the rate constants for reactions involving sulfurbearing species have large uncertainties at low temperature $(150 \mathrm{~K})$, we performed an uncertainty propagation study in our photochemical model. The methodology used is described in Hébrard et al. (2007) and Hébrard et al. (2009). We performed 400 Monte-Carlo runs as a compromise to limit the computation time and to obtain statistically significant results. All the reactions (between hydrocarbons, nitrogen, oxygen, and sulfur species) are treated by the Monte-Carlo procedure simultaneously. Uncertainty factors for modeled mole fractions profiles are not very sensitive to the source of sulfur species as shown for oxygen species in Dobrijevic et al. (2014). Results for Model A2 are presented in Fig. 4 for two species.

Uncertainty on CS profiles is quite low above $400 \mathrm{~km}$ of altitude and increases in the lower stratosphere. These uncertainties clearly do not affect our upper limit for CS significantly. Also, uncertainties on the CS abundance in the higher atmosphere are lower than the difference between the CS abundances given by Models A1 and A2. As a consequence, the detection of CS or even the determination of a low upper limit could be used to distinguish the two external delivery scenarios. For $\mathrm{H}_{2} \mathrm{~S}$ (and many other sulfur species), the uncertainties are very large, especially at altitudes between 200 and $500 \mathrm{~km}$. However, despite these uncertainties, the abundance of $\mathrm{H}_{2} \mathrm{~S}$ remains low since it does not exceed $10^{-10}$. 

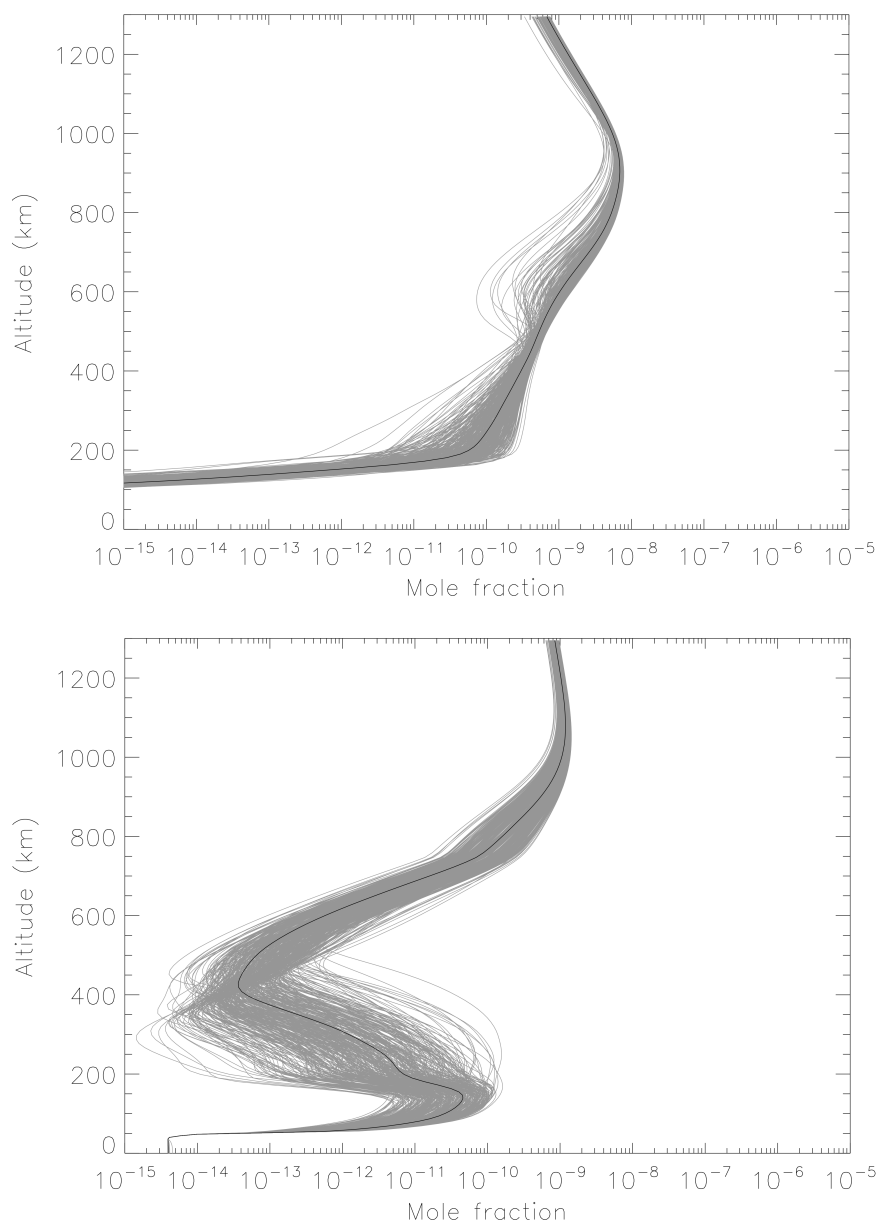

Fig. 4. Abundance profiles of $\mathrm{CS}$ (top) and $\mathrm{H}_{2} \mathrm{~S}$ (bottom) obtained from 400 runs of the Monte-Carlo procedure used to study the propagation of rate constant uncertainties in the photochemical model. Black solid line: initial profile.

\section{Conclusion}

We have developed the first detailed photochemical model of sulfur compounds in the atmosphere of Titan coupling hydrocarbons, nitrogen, oxygen, and sulfur chemistries. Thanks to the efficiency of the cold trap at the tropopause, it is not expected that sulfur-bearing species stemming from cryogenic activity could bring noticeable amounts of sulfur into the stratosphere. We then studied in particular the photochemistry of sulfur species subsequent to a possible external delivery from two different sources (micrometeorites ablation and Enceladus' plume activity) to quantify the abundances of sulfur-bearing species resulting from such sources. We considered that fluxes of sulfur species reflect their relative abundances in comets or in the Enceladus plume with respect to $\mathrm{H}_{2} \mathrm{O}$. The results of our model show that the influx of $\mathrm{H}_{2} \mathrm{~S}$ (together with $\mathrm{OCS}$ and $\mathrm{CS}_{2}$ ) by micrometeorite ablation in the upper atmosphere of Titan leads to a suite of photochemical processes that mainly produce $\mathrm{CS}$ and $\mathrm{H}_{2} \mathrm{CS}$ in the upper atmosphere and $\mathrm{H}_{2} \mathrm{~S}$ in the lower atmosphere with some $\mathrm{CH}_{3} \mathrm{SH}$ (around $300 \mathrm{~km}$ ) and $\mathrm{C}_{3} \mathrm{~S}$ (around $150 \mathrm{~km}$ ). In the Enceladus model, the abundances of $\mathrm{H}_{2} \mathrm{~S}$ and $\mathrm{CS}$ are several orders of magnitude lower than in the micrometeorite ablation scenario. The differences in the sulfur-species abundances between the various scenarios essentially reflect the differences in the input fluxes of sulfur, with some deviations to this general trend caused by the coupled chemistries.
Model uncertainties on CS mole fraction profiles are quite low (especially in the higher stratosphere) compared to the differences obtained by the micrometeorite ablation and Enceladus plume activity sources for sulfur species studied in the present paper. As a consequence, if the very low abundance of sulfur species in Enceladus' plumes is confirmed, a potential detection of CS in the atmosphere of Titan would undoubtedly favor the micrometeorite ablation source for sulfur and possibly oxygen species, whereas determining a low upper limit would favor the Enceladus source.

Acknowledgements. We thank the Programme National de Planétologie (PNP) of the Institut National des Sciences de l'Univers (INSU) for funding a part of this work.

\section{References}

Baulch, D. L., Bowman, C. T., Cobos, C. J., et al. 2005, J. Phys. Chem. Ref. Data, 34, 757

Black, G., \& Jusinski, L. E. 1985, J. Chem. Phys., 82, 789

Bockelée-Morvan, D., Lis, D. C., Wink, J. E., et al. 2000, A\&A, 353, 1101

Cottini, V., Nixon, C. A., Jennings, D. E., et al. 2012, Icarus, 220, 855

Coustenis, A., Salama, A., Lellouch, E., et al. 1998, A\&A, 336, L85

Crovisier, J., Biver, N., Bockelée-Morvan, D., et al. 2009, Earth Moon Planets, 105,267

Cui, J., Yelle, R. V., Vuitton, V., et al. 2009, Icarus, 200, 581

Cupitt, L., \& Glass, G. 1975, Proc. Symp. Chem. Kinet. Data Upper Lower Atmos., 39

de Kok, R., Irwin, P. G. J., Teanby, N. A., et al. 2007, Icarus, 186, 354

Dobrijevic, M., Hébrard, E., Loison, J. C., \& Hickson, K. M. 2014, Icarus, 228, 324

Dunning, T. 1989, J. Chem. Phys., 90, 1007

Feng, R., Cooper, G., \& Brion, C. E. 1999, Chem. Phys., 244, 127

Georgievskii, Y., \& Klippenstein, S. J. 2005, J. Chem. Phys., 122, 194103

Hartogh, P., Lellouch, E., Moreno, R., et al. 2011, A\&A, 532, L2

Hébrard, E., Dobrijevic, M., Bénilan, Y., \& Raulin, F. 2007, Planet. Space Sci., 55,1470

Hébrard, E., Dobrijevic, M., Pernot, P., et al. 2009, J. Phys. Chem., 113, 11227

Hörst, S. M., Vuitton, V., \& Yelle, R. V. 2008, J. Geophys. Res., 113, 10006

Hsu, C. W., Liao, C. L., Ma, Z. X., Tjossem, P. J. H., \& Ng, C. Y. 1992, Chem. Phys. Lett., 199, 78

Jackson, W. M., Halpern, J. B., Feldman, P. D., \& Rahe, J. 1982, A\&A, 107, 385

Judge, R. H., Drury-Lessard, C. R., \& Moule, D. C. 1978, Chem. Phys. Lett., 53, 82

Lara, L. M., Lellouch, E., González, M., Moreno, R., \& Rengel, M. 2014, A\&A, 566, A143

Loison, J.-C., Halvick, P., Bergeat, A., Hickson, K. M., \& Wakelam, V. 2012, MNRAS, 421, 1476

Loison, J. C., Hébrard, E., Dobrijevic, M., et al. 2014, Icarus, in press

Lutz, B. L., de Bergh, C., \& Owen, T. 1983, Science, 220, 1374

Moltzen, E., Klabunde, K., \& Senning, A. 1988, Chem. Rev., 88, 391

Moreno, R., Lellouch, E., Lara, L. M., et al. 2012, Icarus, 221, 753

Nixon, C. A., Teanby, N. A., Irwin, P. G. J., \& Hörst, S. M. 2013, Icarus, 224, 253

Peng, J., Hu, X., \& Marshall, P. 1999, J. Phys. Chem. A, 103, 5307

Rice, B., \& Chabalowski, C. 1994, J. Phys. Chem., 98, 9488

Samuelson, R. E., Maguire, W. C., Hanel, R. A., et al. 1983, J. Geophys. Res., 88,8709

Teanby, N. A., Irwin, P. G. J., de Kok, R., \& Nixon, C. A. 2010, Faraday Discuss., 147,51

Tsang, W. \& Hampson, R. 1986, J. Phys. Chem. Ref. Data, 16, 471

Vinatier, S., Bézard, B., Nixon, C. A., et al. 2010, Icarus, 205, 559

Vuitton, V., Yelle, R. V., Lavvas, P., \& Klippenstein, S. J. 2012, ApJ, 744, 11

Waite, Jr., J. H., Lewis, W. S., Magee, B. A., et al. 2009, Nature, 460, 487

Wakelam, V., Herbst, E., Loison, J.-C., et al. 2012, ApJS, 199, 21

Watanabe, K., \& Jursa, A. S. 1964, J. Chem. Phys., 41, 1650

Wollrab, J., \& Rasmussen, R. 1973, J. Chem. Phys., 58, 4702

Woodney, L. M., McMullin, J., \& A'Hearn, M. F. 1997, Planet. Space Sci., 45 717

Yang, S. C., Freedman, A., Kawasaki, M., \& Bersohn, R. 1980, J. Chem. Phys., 72,4058

Zhao, Y., \& Truhlar, D. 2008, Theoretical Chemistry Accounts, 120, 215 